Article

\title{
Entire Magnetic Integration Method of Multi-Transformers and Resonant Inductors for CLTLC Resonant Converter
}

\author{
Ruixin Liu ${ }^{1}$, Yifeng Wang ${ }^{1, * \mathbb{C}}$, Qing Chen ${ }^{2}$, Fuqiang Han ${ }^{3}$ and Zhun Meng ${ }^{4}$ \\ 1 School of Electrical and Information Engineering, Tianjin University, Tianjin 300072, China; \\ rxliu1210@tju.edu.cn \\ 2 State Grid Jiangsu Electric Power Company, Nanjing 210024, China; dgg6289@sohu.com \\ 3 State Grid Nanjing Power Supply Company, Nanjing 210019, China; fqhanyz@foxmail.com \\ 4 State Grid Tianjin Economic Research Institute, Tianjin 300210, China; quakermaster@sohu.com \\ * Correspondence: wayif@tju.edu.cn
}

Received: 7 July 2020; Accepted: 25 August 2020; Published: 27 August 2020

\begin{abstract}
An entire magnetic integration methodology of high efficiency printed circuit board (PCB) winding transformer for CLTLC (capacitor-inductor-transformer-inductor-capacitor) resonant converter is presented. All magnetic components in the converter, including two resonant inductors and two transformers, are integrated into an improved EIE (E-type and I-type and E-type) core structure. According to the matrix transformer concept and uneven winding distribution, the novel structure can be obtained by introducing an air gap to the center core leg. Thus, the magnetizing inductance and leakage inductance of the transformer can be controlled easily through adjusting the air gap reluctances. In addition, both the detailed mathematical analysis and the reluctance model of the transformer have been studied. Furthermore, a four-layer printed circuit board winding structure is chosen. The related winding arrangement is also discussed in depth. Finally, a $1 \mathrm{~kW}$ prototype with the presented structure is implemented to verify the validity of the theoretical analysis. Experimental results demonstrate that the proposed structure guarantees high efficiency within the entire load range. Peak efficiency of $96.62 \%$ can be ensured.
\end{abstract}

Keywords: high efficiency; resonant converter; integrated inductor; PCB winding transformer; uneven winding distribution

\section{Introduction}

Featured with high frequency, high efficiency, high power density and low electromagnetic interference (EMI), resonant DC-DC converters have aroused widespread public concerns [1-3]. Owing to the quantities and diverse connection ways of passive components (including capacitors, inductors and transformers) in the resonant unit, the flexible resonant characteristics can be achieved. In view of the endless research on this kind of converters, the topologies could be numerous [4-8].

Moreover, with the rapid development of wide band gap semiconductor devices, the momentum towards high frequency, miniaturization and lightweight is further proposed for resonant DC-DC converters. The design of magnetic components, namely inductors and transformers, is the key factor to achieve the above targets. In general, the volume, weight and cost of the magnetic parts dominate the whole converter's efficiency, power density and heat dissipation. Nevertheless, traditional magnetic components with litz wires and copper foils as their windings, possess some inherent limitations, such as large volume, high power losses and complex fabrication process. Thereby, it usually results in the difficulty of performance promotion. In contrast, the planar magnetic components with the printed circuit board (PCB) windings emerge as the promising candidates [9-13]. Different from the 
conventional core structure, the planar transformer based on the low-profile core can not only help reduce the size of the magnetics, but also enlarge the heat dissipation area to lower the temperature. Furthermore, this technology can offer the improved reliability of the manufacturing process, so as to ensure the good consistency of products. Besides, the planarization of the core also promotes the investigation of the planar windings. Therefore, the primary and secondary windings are closely coupled to reduce eddy current losses effectively.

Through the employment of the planar magnetic components, high efficiency and automatic production can be harvested simultaneously, especially for the resonant converters with more magnetic components in the resonant units. However, the issues of a large number of magnetic components and subsequent large volume still exist. As a result, further efforts need to be made.

Fortunately, magnetic integration technology has proven to be an effective means of addressing the above issues. It could integrate multiple magnetic parts into one module. In such way, the whole integrated module is functionally equivalent to these multiple magnetic components. Consequently, a large number of magnetic components can be effectively shrunk. And the resulting power density is improved as well [14-16].

A variety of integrating schemes are reported in [17-21]. In [17], an integrated module is constructed for two inductors. Through the utilization of phase-interleaved currents, the proposed structure holds advantages of lower size and losses. For the integration of inductor and transformer, some researchers have improved or combined the core structure to achieve preferable performances. An EIE (E-type and I-type and E-type) core geometry is presented and analyzed in [18] to integrate the discrete magnetic elements. The design approach can decouple the transformer and inductor successfully, leading to their independent operation and control. Thereby, lower footprint and higher efficiency are both acquired. Under some conditions, it is preferred to serve the leakage inductor as the desirable inductor to diminish the overall size. In consequence, selecting low-permeability material as a magnetic shunt is a good way to build the desirable leakage inductance. Literature [19] proposes a novel method to create a larger resonant inductor through the adoption of the magnetic shunt. In this case, the series-connected inductor can be effectively integrated with the transformer. In [20], the magnetic shunt is inserted in the middle of the core window to increase the leakage inductance. With this structure, the desirable leakage inductance can be gained by adjusting the relative permeability and thickness of the shunt. Typically, the employment of a magnetic shunt suffers from structural complexity as well.

In this paper, the CLTLC (capacitor-inductor-transformer-inductor-capacitor) multi-resonant converter with dual transformer structure proposed by [8] is taken as the research object. Beneficial from the specific structure, the fundamental and third-order harmonic active power can be transferred simultaneously within a wide frequency range. Besides, the full-range soft-switching characteristics and high conversion efficiency are both guaranteed. Despite the above merits, the multiple magnetic components within its resonant unit result in the complex fabricating process and large volume as well, which compromises its extensive applications. In this regard, this topology needs further investigation and improvement. Correspondingly, this paper presents an effective integration method with the improved EIE core structure to integrate all the discrete magnetic components. Due to the series connection of inductor and transformer, the leakage inductor can be used as the resonant inductor. Specifically, through adjusting the air gap reluctances of different core legs, the flexible and separate control of magnetizing inductance and leakage inductance can be well attained. In this way, the reduced volume of magnetic components, manufacturing simplicity and high conversion efficiency are all harvested. Finally, experimental results demonstrate the effectiveness of theoretical analysis and integrated design.

The specific arrangements of the article are structured as follows. In Section 2, the concept of matrix transformer and the idea of unbalanced winding distribution are firstly developed. Then, the reluctance model is built to verify the effectiveness of the novel transformer structure with a controllable leakage inductance. The winding arrangement and core structure are discussed in Section 3. Section 4 shows the corresponding experimental results. Then, Section 5 summarizes the whole paper. 


\section{Investigation of Magnetic Integration Solution}

\subsection{Investigation of Matrix Transformer}

A multi-resonant soft-switching CLTLC DC-DC converter with traditional magnetic components was proposed in literature [8]. Its topology is redrawn in Figure 1. As shown, there are in total six elements in the resonant unit, including two resonant capacitors $\left(C_{1}, C_{2}\right)$, two resonant inductors $\left(L_{1}, L_{2}\right)$, and two high-frequency transformers $\left(T_{1}, T_{2}\right)$. Besides, the half-bridge $\left(S_{1}-S_{2}\right)$ is adopted in the inverter unit, and the diode rectifier $\left(D_{1}-D_{4}\right)$ is employed in the rectifier unit. Beneficial from the reasonable placement of three resonant frequencies, not only the fundamental component but also the third-order harmonic component can be effectively transmitted. The resonant current utilization is greatly enhanced correspondingly.

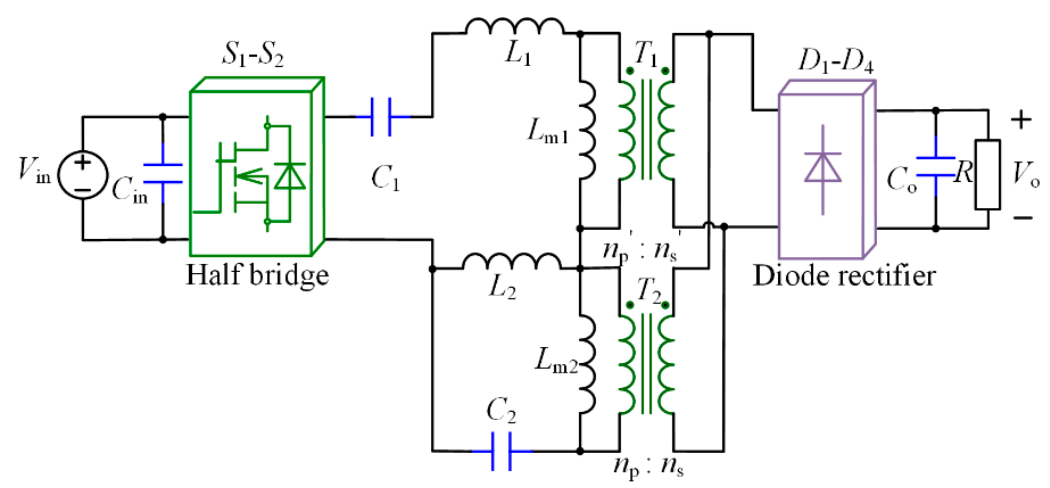

Figure 1. Topology of the capacitor-inductor-transformer-inductor-capacitor (CLTLC) converter.

However, the abovementioned magnetic components (including inductors and transformers) in the resonant unit are all discrete magnetic components. Even implemented with planar magnetics, they still take a large share both in number and volume, resulting in increased losses and deteriorated efficiency as well. To deal with this problem, this paper proposes an improved EIE core structure to integrate all these four magnetic components. Correspondingly, the volume and related losses of the magnetic components are greatly reduced, the performances of the converter are also improved. The detailed design method is described below.

Matrix transformer concept proposed by literature [21] is an effective way to improve the characteristics of the transformer. Its essence is the combination of a series of basic transformers $\left(T_{1}, T_{2}, \ldots, T_{k}\right)$, making them function equally as a single transformer $T$. Specifically, each elemental transformer owns a set of turns ratio $\left(n_{\mathrm{p} 1}: n_{\mathrm{s} 1}, n_{\mathrm{p} 2}: n_{\mathrm{s} 2}, \ldots, n_{\mathrm{pk}}: n_{\mathrm{sk}}\right)$. Then, through the appropriate connection (namely in series or in parallel) of the primary and secondary windings of these transformers, the desired turns ratio $\left(n_{\mathrm{p}}: n_{\mathrm{s}}\right)$ can be satisfied.

The matrix transformer with PCB windings shows the eminent advantages of reduced leakage inductance and winding losses. Whereas, when this method is applied to the CLTLC converter, the number of transformers and the consequent core loss will increase. In this case, with the extra introduced transformer cores, the overall volume as well as the conversion efficiency of the converter, may not be promoted accordingly. Besides, this scheme only improves the performance of the transformer instead of the inductor. Furthermore, as indicated in [21], through the adoption of elemental transformers with fully even distribution windings, the flux passing through the center leg can be completely canceled after the winding rearrangement. In this way, the generated leakage inductance by the transformer is too small to serve as the resonant inductance. In particular, for the CLTLC converter, the external inductor component is still required, leading to the increase both in the number and volume of the magnetic components. Consequently, the integration degree of this converter needs to be further improved. 


\subsection{Investigation of Uneven Distribution Windings}

As discussed above, the resonant inductor is connected in series with the transformer in CLTLC converter. Thus, serving the leakage inductor of the transformer as the resonant inductor is a good way to simplify the magnetic integration scheme.

In this section, to achieve better-integrated effect, further adjustment of the windings is considered to be conducted. To attain the expected leakage inductance, the magnetic flux uncoupled between primary and secondary windings should be created. Thus, the unevenly distributed winding is employed to construct the leakage inductance instead of the evenly distributed winding.

It is worth mentioning that, based on the parameter design method proposed in [8], the main specifications of a $1 \mathrm{~kW}$ prototype can be easily obtained. The turns ratios of $T_{1}$ and $T_{2}$ are $6: 1$ and 1:2, respectively. Resonant inductors $L_{1}$ and $L_{2}$ are $25 \mu \mathrm{H}$ and $24 \mu \mathrm{H}$, respectively. The main parameters of the converter are listed in Table 2 in Section 4. Since the design process is not the focus of this paper and has been discussed in detail in [8], it will not be presented repeatedly here.

Take transformer $T_{2}$ as an example, the derivate method is briefly described as follows. To start with, $T_{2}$ is divided into two elemental transformers $T_{21}$ and $T_{22}$ with UI (U-type and I-type) cores, as shown in Figure 2. Their turns ratios are set at 3:3 and 1:5, respectively.
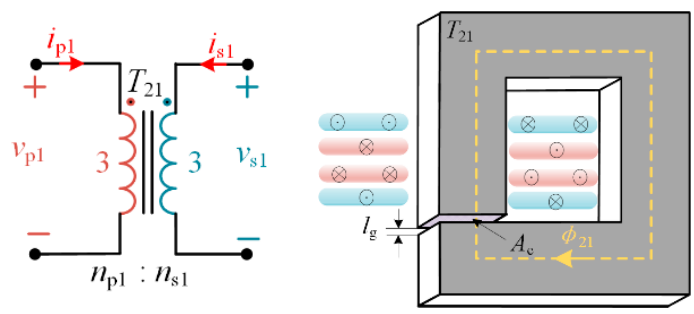

(a)
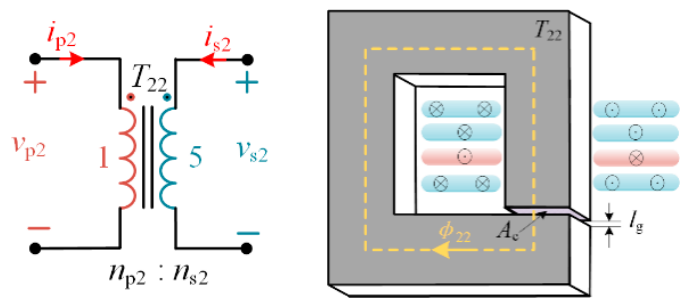

(b)

Figure 2. Transformer $T_{2}$ with the uneven winding distribution. (a) Winding connection and UI (U-type and I-type) core structure of $T_{21}$, (b) winding connection and UI core structure of $T_{22}$.

For each elemental transformer $T_{21}$ and $T_{22}$, their inductive electromotive force includes self-induction electromotive force and mutual-induction electromotive force [22]. To simplify the analysis, the following three assumptions are made to fulfill the design requirements without losing accuracy:

(1) The permeability of the magnetic core is much greater than that of the air, so the core reluctance is negligible compared to the air reluctance.

(2) Flux leakage in the air is very small and can be ignored as well.

(3) Under the magnetic circuit analysis, the influence of the fringing flux of magnetic fields is not considered.

Then, the self-inductance and mutual-inductance matrices for these two transformers can be written as (1) and (2). Here, $v_{\mathrm{p} 1}, v_{\mathrm{p} 2}$ and $v_{\mathrm{s} 1}, v_{\mathrm{s} 2}$ are the primary-side voltages and secondary-side voltages of $T_{21}$ and $T_{22}$, respectively. $i_{\mathrm{p} 1}, i_{\mathrm{p} 2}$ and $i_{\mathrm{s} 1}, i_{\mathrm{s} 2}$ represent their corresponding currents. 
The reluctance of the air gap is defined as $R_{\mathrm{g}}$ and listed in (3). Where $l_{\mathrm{g}}$ and $A_{\mathrm{c}}$ denote the air gap length and cross-sectional area of the core leg. $\mu_{\mathrm{r}}$ and $\mu_{0}$ are the relative permeability and vacuum permeability, respectively.

Further, the above two transformers can be arranged in a specific way to ensure that the desirable turns ratio of 1:2 is guaranteed for transformer $T_{2}$. Specifically, Figure 3 shows the corresponding connection way. As seen, for $T_{21}$ and $T_{22}$, both of their primary windings and secondary windings are connected in series. In this case, the original two UI cores are equivalently substituted with one EI (E-type and I-type) core. From Figure 3a, the relationship between voltage and current among these three transformers is expressed as (4). Where, $v_{\mathrm{p}}$ and $v_{\mathrm{s}}$ are the primary-side voltage and secondary-side voltage of $T_{2}, i_{\mathrm{p}}$ and $i_{\mathrm{s}}$ are the corresponding currents.

$$
\begin{gathered}
{\left[\begin{array}{c}
v_{\mathrm{p} 1} \\
v_{\mathrm{s} 1}
\end{array}\right]=\left[\begin{array}{cc}
\frac{9}{R_{\mathrm{g}}} & \frac{9}{R_{\mathrm{g}}} \\
\frac{9}{R_{\mathrm{g}}} & \frac{9}{R_{\mathrm{g}}}
\end{array}\right]\left[\begin{array}{c}
\frac{d i_{\mathrm{p} 1}}{d t} \\
\frac{d i_{\mathrm{s} 1}}{d t}
\end{array}\right]} \\
{\left[\begin{array}{c}
v_{\mathrm{p} 2} \\
v_{\mathrm{s} 2}
\end{array}\right]=\left[\begin{array}{ll}
\frac{1}{R_{\mathrm{g}}} & \frac{5}{R_{\mathrm{g}}} \\
\frac{5}{R_{\mathrm{g}}} & \frac{25}{R_{\mathrm{g}}}
\end{array}\right]\left[\begin{array}{c}
\frac{d i_{\mathrm{p} 2}}{d t} \\
\frac{d i_{\mathrm{s} 2}}{d t}
\end{array}\right]} \\
R_{\mathrm{g}}=\frac{l_{\mathrm{g}}}{\mu_{\mathrm{r}} \mu_{0} A_{\mathrm{c}}} \\
\left\{\begin{array}{c}
v_{\mathrm{p}}=v_{\mathrm{p} 1}+v_{\mathrm{p} 2} \\
v_{\mathrm{s}}=v_{\mathrm{s} 1}+v_{\mathrm{s} 2} \\
i_{\mathrm{p}}=i_{\mathrm{p} 1}=i_{\mathrm{p} 2} \\
i_{\mathrm{s}}=i_{\mathrm{s} 1}=i_{\mathrm{s} 2}
\end{array}\right.
\end{gathered}
$$

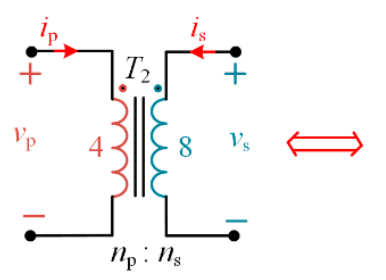

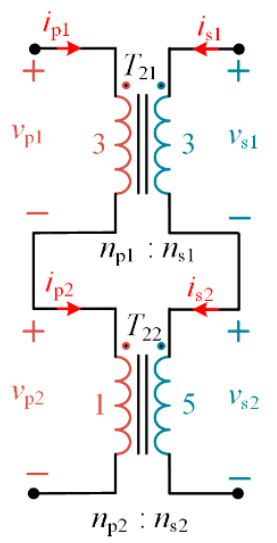

(a)

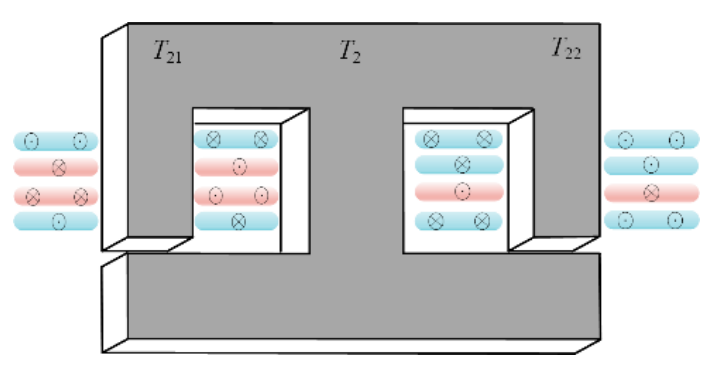

(b)

Figure 3. Equivalent winding connection way and EI (E-type and I-type) core structure of $T_{2}$ (a) equivalent connection way of $T_{2},(\mathbf{b})$ EI core structure of $T_{2}$.

Combing (1)-(4), the resulted self-inductance and mutual-inductance matrix is

$$
\left[\begin{array}{c}
v_{\mathrm{p}} \\
v_{\mathrm{s}}
\end{array}\right]=\left[\begin{array}{ll}
L_{11} & L_{12} \\
L_{12} & L_{22}
\end{array}\right]\left[\begin{array}{l}
\frac{d i_{\mathrm{p}}}{d t} \\
\frac{d i_{\mathrm{s}}}{d t}
\end{array}\right]=\left[\begin{array}{cc}
\frac{10}{R_{\mathrm{g}}} & \frac{14}{R_{\mathrm{g}}} \\
\frac{14}{R_{\mathrm{g}}} & \frac{34}{R_{\mathrm{g}}}
\end{array}\right]\left[\begin{array}{l}
\frac{d i_{\mathrm{p}}}{d t} \\
\frac{d i_{\mathrm{s}}}{d t}
\end{array}\right]
$$

$L_{11}$ and $L_{12}$ are the self-inductances of primary-side winding and secondary-side winding, respectively. $L_{12}$ represents the mutual-inductance [22]. To calculate the magnetizing inductor $L_{\mathrm{m}}$, primary leakage inductor $L_{\mathrm{k} 1}$ and secondary leakage inductor $L_{\mathrm{k} 2}$, the transformer T-mode is built. For transformer $T_{2}$ in Figure 4, the magnetizing inductor is $L_{\mathrm{m} 2}$. The leakage inductors of the primary winding and secondary winding are denoted as $L_{\mathrm{k} 21}$ and $L_{\mathrm{k} 22}$, respectively. 


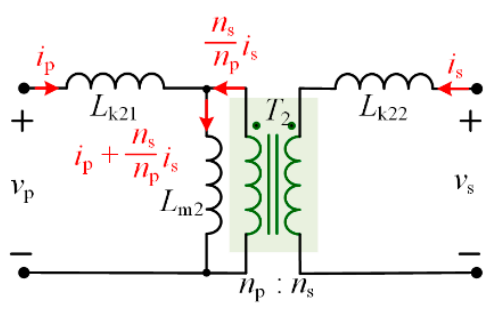

Figure 4. T-model of the transformer $T_{2}$.

From Figure 4, according to the Kirchhoff Voltage Law, the primary-side voltage $v_{p}$ can be obtained by

$$
\begin{aligned}
v_{\mathrm{p}} & =L_{\mathrm{k} 21} \frac{d i_{p}}{d t}+L_{\mathrm{m} 2} \frac{d\left(i_{p}+\frac{n_{s}}{n_{p}} i_{s}\right)}{d t} \\
& =\left(L_{\mathrm{k} 21}+L_{\mathrm{m} 2}\right) \frac{d i_{p}}{d t}+\left(\frac{n_{s}}{n_{p}} L_{\mathrm{m} 2}\right) \frac{d i_{s}}{d t}
\end{aligned}
$$

Then, the relationship between $L_{\mathrm{m} 2}, L_{\mathrm{k} 21}$ and $L_{11}, L_{12}$ can be calculated as

$$
\begin{gathered}
L_{11}=L_{\mathrm{k} 21}+L_{\mathrm{m} 2} \\
L_{12}=\frac{n_{\mathrm{s}}}{n_{\mathrm{p}}} L_{\mathrm{m} 2}
\end{gathered}
$$

Accordingly, by converting the magnetizing inductor to the secondary side, the expression of $L_{22}$ can be acquired.

$$
L_{22}=L_{\mathrm{k} 22}+\left(\frac{n_{\mathrm{s}}}{n_{\mathrm{p}}}\right)^{2} L_{\mathrm{m} 2}
$$

By solving the derived Equations (5), (7)-(9), we can calculate $L_{\mathrm{m} 2}, L_{\mathrm{k} 21}, L_{\mathrm{k} 22}$ as follows.

$$
L_{\mathrm{m} 2}=\frac{7}{R_{\mathrm{g}}}, L_{\mathrm{k} 21}=\frac{3}{R_{\mathrm{g}}}, L_{\mathrm{k} 22}=\frac{6}{R_{\mathrm{g}}}
$$

It is obviously seen from (10) that, in addition to the magnetizing inductor $L_{\mathrm{m} 2}$, the integrated EI core structure depicted in Figure 3 also possesses the built-in leakage inductor $L_{\mathrm{k} 21}$ and $L_{\mathrm{k} 22}$. Moreover, all these three parameters are only inversely proportion to the air gap reluctance $R_{\mathrm{g}}$. Furthermore, for the deformation of (10), we have

$$
L_{\mathrm{k} 21}=\frac{3}{7} L_{\mathrm{m} 2}, L_{\mathrm{k} 22}=\frac{6}{7} L_{\mathrm{m} 2}
$$

Together with (10) and (11), with the mentioned structure shown in Figure 3, there is a direct and confirmed proportional relationship between the leakage inductance and magnetizing inductance. That is to say, when the required magnetizing inductance is obtained through adjusting the air gap reluctance, the leakage inductance is also determined accordingly and remained unchanged. With this structure, the magnetizing inductance and leakage inductance could not be controlled independently and flexibly. In order to control the magnetizing inductance and leakage inductance, the core structure still needs improvements.

Beneficial from the series connection of the resonant inductor and the transformer, the primary leakage inductor can function as the resonant inductor in both $T_{1}$ and $T_{2}$. Moreover, the influence of the secondary leakage inductance is not concerned in the following analysis. Specifically, transformer $T_{2}$ owns relatively small shared power compared to $T_{1}$, so the effect of its secondary leakage inductance is negligible. Transformer $T_{1}$ is a step-down transformer with few secondary windings, thus its secondary leakage inductance can also be ignored in this case. 
Based on Figure 3, an improved EI core structure is proposed and demonstrated in Figure 5. Compared to Figure 3, a new air gap with the length of $l_{\mathrm{gb}}$ is introduced to the center leg of the $\mathrm{E}$ core. Whereas, the length of the air gap of side legs is set as $l_{\text {ga }}$. Moreover, the cross-sectional area of the center leg and side legs is defined as $A_{\mathrm{c}}{ }^{\prime}$ and $A_{\mathrm{c}}$, respectively. In such way, the desirable air gap reluctance can be achieved by modifying the cross-sectional area and the length of the air gap. In (12), the air gap reluctances of side legs and center leg are expressed as $R_{\mathrm{ga}}$ and $R_{\mathrm{gb}}$, respectively. Then, through the different combinations of $R_{\mathrm{ga}}$ and $R_{\mathrm{gb}}$, the magnetizing inductance and leakage inductance can be flexibly controlled. The detailed analysis process will be described in the next part.

$$
R_{\mathrm{ga}}=\frac{l_{\mathrm{ga}}}{\mu_{\mathrm{r}} \mu_{0} A_{\mathrm{c}}}, R_{\mathrm{gb}}=\frac{l_{\mathrm{gb}}}{\mu_{\mathrm{r}} \mu_{0} A_{\mathrm{c}}^{\prime}}
$$

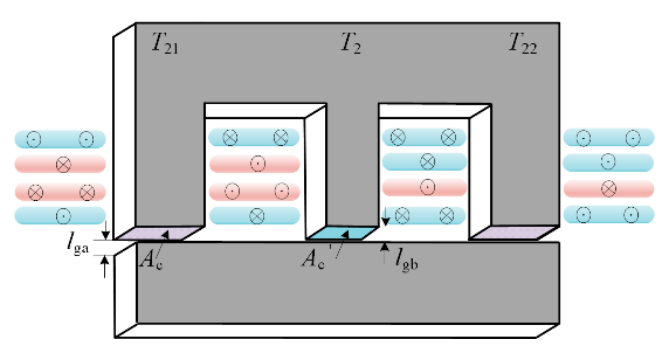

Figure 5. Improved EI core structure of $T_{2}$.

\subsection{Reluctance Model}

According to the improved integrated structure shown in Figure 5, the corresponding reluctance model can be established in Figure 6. The corresponding variables in the improved EI core structure are added by a superscript (') to distinguish from the EI core structure shown in Figure 3. In other words, the primary leakage inductor and magnetizing inductor of $T_{2}$ are redefined as $L_{\mathrm{k} 21}{ }^{\prime}$ and $L_{\mathrm{m} 2}{ }^{\prime}$, respectively. For precision, the assumptions are kept consistent with the previous analysis to simplify the model.

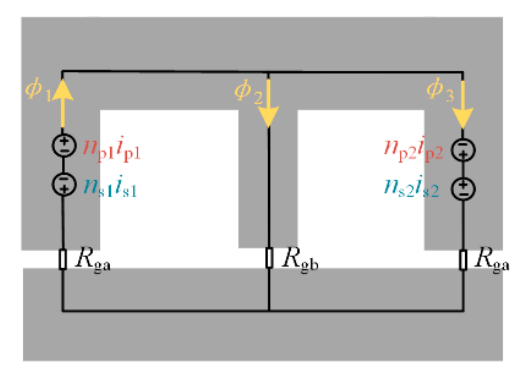

Figure 6. The equivalent reluctance model of the improved EI core structure.

In Figure $6, n_{\mathrm{p} 1}, n_{\mathrm{p} 2}$ and $n_{\mathrm{s} 1}, n_{\mathrm{s} 2}$ are the primary-side turns and secondary-side turns of the left-side leg and right-side leg, respectively.

$\Phi_{1}, \Phi_{3}$ and $\Phi_{2}$ are the flux flowing through the left, right and center legs, with their directions indicated by the yellow arrows in the figure. The magnetic flux of each leg can be derived and listed in (13) combined with Figure 6.

$$
\left\{\begin{array}{l}
\Phi_{1}=\frac{\left(n_{\mathrm{p} 1} i_{\mathrm{p} 1} R_{\mathrm{ga}}+n_{\mathrm{p} 1} i_{\mathrm{p} 1} R_{\mathrm{gb}}+n_{\mathrm{p} 2} i_{2} R_{\mathrm{gb}}\right)-\left(n_{\mathrm{s} 1} i_{\mathrm{s} 1} R_{\mathrm{ga}}+n_{\mathrm{s} 1} i_{\mathrm{s} 1} R_{\mathrm{gb}}+n_{\mathrm{s} 2} i_{\mathrm{s} 2} R_{\mathrm{gb}}\right)}{R_{\mathrm{ga}}\left(R_{\mathrm{ga}}+2 R_{\mathrm{gb}}\right)} \\
\Phi_{2}=\frac{n_{\mathrm{p} 1} i_{\mathrm{p} 1}-n_{\mathrm{p} 2} i_{\mathrm{p} 2}+n_{\mathrm{s} 2} i_{\mathrm{s} 2}-n_{\mathrm{s} 1} i_{\mathrm{s} 1}}{R_{\mathrm{ga}}+2 R_{\mathrm{gb}}} \\
\Phi_{3}=\frac{\left(n_{\mathrm{p} 1} i_{\mathrm{p} 1} R_{\mathrm{gb}}+n_{\mathrm{p} 2} i_{\mathrm{p} 2} R_{\mathrm{ga}}+n_{\mathrm{p} 2} i_{\mathrm{p} 2} R_{\mathrm{gb}}\right)-\left(n_{\mathrm{s} 1} i_{\mathrm{s} 1} R_{\mathrm{gb}}+n_{\mathrm{s} 2} i_{\mathrm{s} 2} R_{\mathrm{ga}}+n_{\mathrm{s} 2} i_{\mathrm{s} 2} R_{\mathrm{gb}}\right)}{R_{\mathrm{ga}}\left(R_{\mathrm{ga}}+2 R_{\mathrm{gb}}\right)}
\end{array}\right.
$$


According to the actual turns of each elemental transformers of $T_{2},(13)$ can be simplified as

$$
\left\{\begin{array}{l}
\Phi_{1}=\frac{\left(3 R_{\mathrm{ga}}+4 R_{\mathrm{gb}}\right) i_{\mathrm{p}}-\left(3 R_{\mathrm{ga}}+8 R_{\mathrm{gb}}\right) i_{\mathrm{s}}}{R_{\mathrm{ga}}\left(R_{\mathrm{ga}}+2 R_{\mathrm{gb}}\right)} \\
\Phi_{2}=\frac{2 i_{\mathrm{p}}+2 i_{\mathrm{s}}}{R_{\mathrm{ga}}+2 R_{\mathrm{gb}}} \\
\Phi_{3}=\frac{\left(R_{\mathrm{ga}}+4 R_{\mathrm{gb}}\right) i_{\mathrm{p}}-\left(5 R_{\mathrm{ga}}+8 R_{\mathrm{gb}}\right) i_{\mathrm{s}}}{R_{\mathrm{ga}}\left(R_{\mathrm{ga}}+2 R_{\mathrm{gb}}\right)}
\end{array}\right.
$$

Besides, according to the Faraday law and T-model in Figure 5, the expressions of primary-side voltage and secondary-side voltage are

$$
\begin{aligned}
& v_{\mathrm{p}}=L_{11} \frac{d i_{\mathrm{p}}}{d t}+L_{12} \frac{d i_{\mathrm{s}}}{d t}=n_{\mathrm{p}} \frac{d \varphi}{d t} \\
& v_{\mathrm{s}}=L_{12} \frac{d i_{\mathrm{p}}}{d t}+L_{22} \frac{d i_{\mathrm{s}}}{d t}=-n_{\mathrm{s}} \frac{d \varphi}{d t}
\end{aligned}
$$

Further, the following expressions are listed for those two variables $\left(L_{\mathrm{m} 2}{ }^{\prime}, L_{\mathrm{k} 21}{ }^{\prime}\right)$.

$$
\begin{gathered}
L_{\mathrm{k} 21}{ }^{\prime}+L_{\mathrm{m} 2}{ }^{\prime}=\frac{\left.\left(n_{\mathrm{p} 1} \varphi_{1}+n_{\mathrm{p} 2} \varphi_{3}\right)\right|_{i_{\mathrm{s}}=0}}{i_{\mathrm{p}}} \\
L_{\mathrm{m} 2^{\prime}}=\frac{\left.\left(n_{\mathrm{s} 1} \varphi_{1}+n_{\mathrm{s} 2} \varphi_{3}\right)\right|_{i_{s}=0}}{i_{\mathrm{p}}}
\end{gathered}
$$

By solving the above equations, we can attain

$$
\left\{\begin{array}{l}
L_{\mathrm{m} 2}{ }^{\prime}=\frac{16}{R_{\mathrm{ga}}}-\frac{2}{R_{\mathrm{ga}}+2 R_{\mathrm{gb}}} \\
L_{\mathrm{k} 21^{\prime}}=\frac{8}{R_{\mathrm{ga}}+2 R_{\mathrm{gb}}}-\frac{8}{R_{\mathrm{ga}}}
\end{array}\right.
$$

It is indicated by (19) that, for the structure depicted in Figure 5, both of the magnetizing inductance and leakage inductances of the transformer are related to the air gap reluctance $R_{\mathrm{ga}}$ and $R_{\mathrm{gb}}$. Therefore, for the desired magnetizing inductance and leakage inductance, the air gap reluctances $R_{\mathrm{ga}}$ and $R_{\mathrm{gb}}$ can be determined.

In addition, from (12), the air gap reluctance is the function of the air gap length and the cross-sectional area of the core leg. The adjustment of these two variables can change the value of the air gap reluctance. On this basis, it is clear that the magnetizing inductance and leakage inductance can be flexibly controlled by changing the air gap length and cross-section area. In other words, the resonant inductor can be fully substituted with the leakage inductor of the transformer. Under this condition, the transformer and the resonant inductor are integrated into one core accordingly.

The above derivative process can also be applied to the transformer $T_{1}$ and not discussed here. In summary, the superiority of the improved EI core geometry is obvious. Concretely, by changing the air gap reluctances of different magnetic legs, the magnetizing inductance and leakage inductance of the transformer can be ultimately determined. By this means, the leakage inductor is controllable and fully operated as the resonant inductor. Different from the conventional EI core, the leakage inductor can be controlled by the center leg in the improved core structure. In particular, if the center leg's air gap reluctance is smaller compared to side legs, the more leakage flux will pass through, the higher the leakage inductor will be, and vice versa.

With this method, although the inductor losses are completely eliminated, the transformer losses increase as a result of the additional leakage flux flowing within the magnetic core. This may result in the bad thermal characteristic of the transformer. However, this design method is still instructive for the magnetic integration design of the multi-resonant converters. 


\section{Winding Arrangement and Integrated Core Structure}

The winding arrangement for the modified transformers $T_{1}$ and $T_{2}$ are illustrated in this section. In the following figures, the yellow arrow indicates the leakage flux direction within the core, the current direction is also marked. Based on the idea of uneven winding distribution, for both $T_{1}$ and $T_{2}$, more primary windings are placed on the left leg and more secondary windings are distributed on the right leg. Due to the redistributed windings, there is a flux passing through the center leg, which is not fully coupled between the primary and secondary windings. By definition, that is the leakage flux. The partial coupling of the flux results in leakage inductance [20]. In addition, the implementation of the four-layer PCB board is used for its relatively low cost and easy fabrication.

Figure 7 shows the detailed integration scheme of $T_{2}$, which is composed of $T_{21}$ and $T_{22}$. With regard to $T_{21}$, the top layer and bottom layer are the secondary windings, while the remaining two layers are the primary windings. Besides, the primary windings of $T_{22}$ are located in Layer 3, and secondary windings are laid in Layer 1, Layer 2 and Layer 4. Furthermore, relatively good interleaving is ensured by this winding distribution to obtain the efficient conversion.

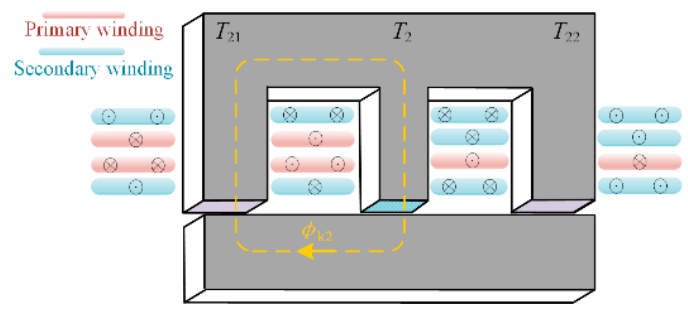

Figure 7. Integration scheme of $T_{2}$.

Similar to $T_{2}$, the integration scheme with the detailed winding distribution of $T_{1}$ is given in Figure 8. However, the winding distribution of $T_{1}$ is quite different from that of $T_{2}$. Specifically, the middle layers of primary windings are connected in series, the top and the bottom layers (Layer 1 and Layer 4) of secondary windings are in parallel. Due to the adoption of a parallel connection of windings, the current carrying capacity of the transformer is improved [21]. The winding arrangement of Layer 1 and Layer 4 is exactly the same.

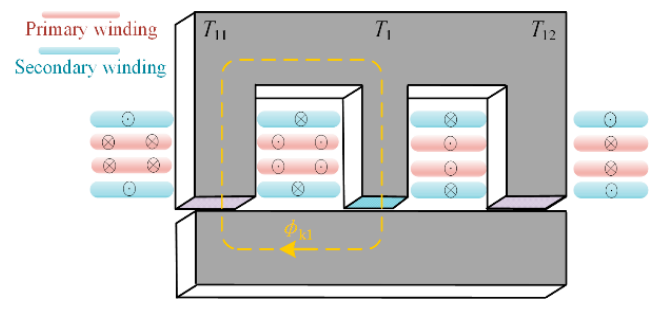

Figure 8. Integration scheme of $T_{1}$.

From Figures 7 and 8, the current direction of each element transformer is opposite, so is the direction of magnetic flux in the middle leg generated by them. Thus, the partial flux cancellation is obtained, and the length of the middle leg can be shrunk properly.

The detailed winding arrangement for the modified matrix transformers $T_{2}$ and $T_{1}$ are illustrated in Figures 9 and 10, respectively. They correspond well to Figures 7 and 8. In both figures, the yellow arrow indicates the current direction within the secondary windings. The red arrow denotes the current direction passing through the primary windings. Since the same windings are distributed in different PCB layers, vias is adopted to connect these layers. 


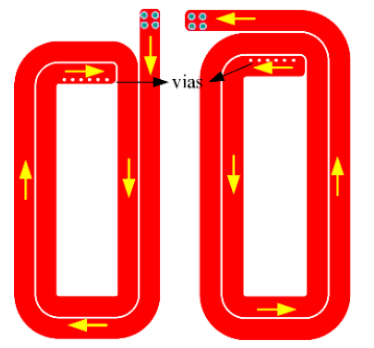

(a)

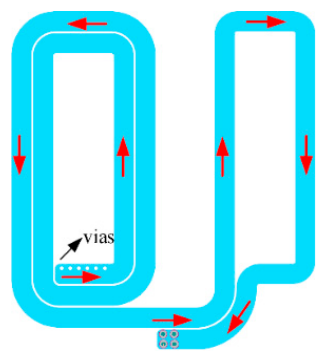

(c)
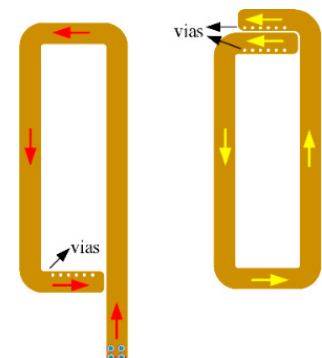

(b)

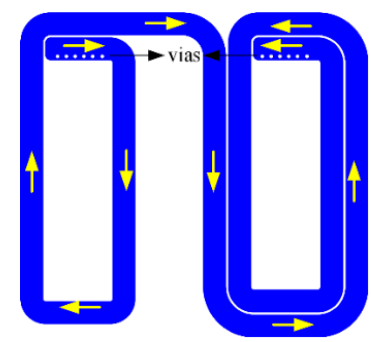

(d)

Figure 9. Winding arrangement for transformer $T_{2}$ (a) Layer 1, (b) Layer 2, (c) Layer 3, (d) Layer 4.

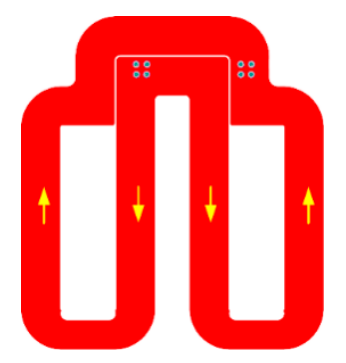

(a)

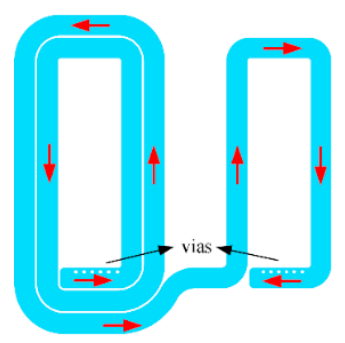

(c)

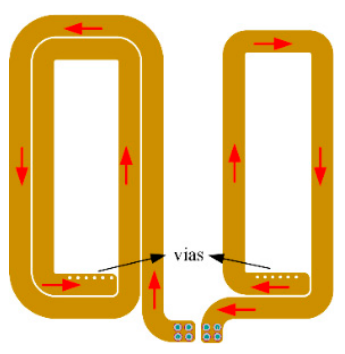

(b)

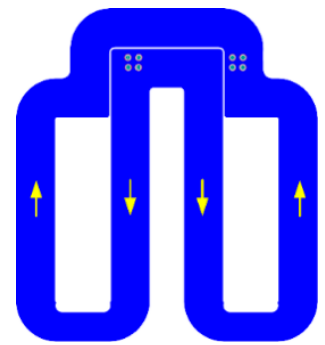

(d)

Figure 10. Winding arrangement for transformer $T_{1}$. (a) Layer 1. (b) Layer 2. (c) Layer 3. (d) Layer 4.

As stated above, with the proposed improved EI core structure, a discrete transformer and a discrete resonant inductor can be simultaneously integrated into one core. Since there are four magnetic components (including two inductors and two transformers) in the resonant unit, to further enhance the properties of the transformer, an improved EIE core structure, shown in Figure 11, is proposed. As seen from this figure, when compared with two separate EI cores, one I-type core can be eliminated. Moreover, the remaining common I-type core provides a low reluctance path, thus each transformer can be operated independently. The improved EIE structure just combines two EI cores structurally, but does not change their winding distribution. 


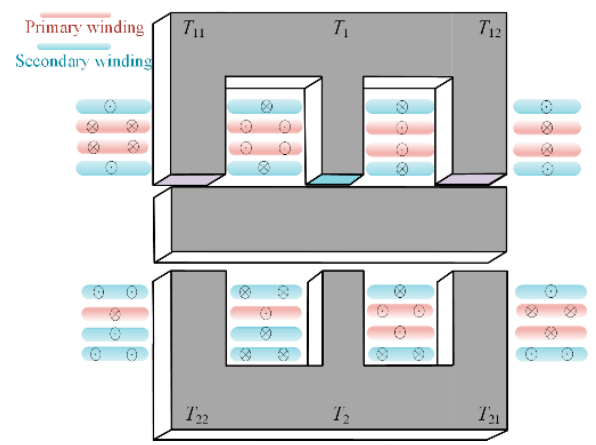

Figure 11. Integration scheme of CLTLC converter.

To validate the theoretical analysis, a two-dimensional finite element analysis (FEA) simulation model of the presented EIE magnetic integration scheme is built in Maxwell. The magnetic flux density $B$ within the core and magnetic field $H$ in the air are depicted in Figure 12. It is obvious that, due to the uneven winding distribution, a large amount of magnetic flux concentrates on the center leg. Based on the above analysis, most of it is leakage flux. Even so, the flux of the core is not saturated, and the maximum value of magnetic flux density is also limited reasonably. Compared with the core, there is less leakage flux in the air, having little impact on surrounding components, reducing EMI and eddy current losses accordingly.
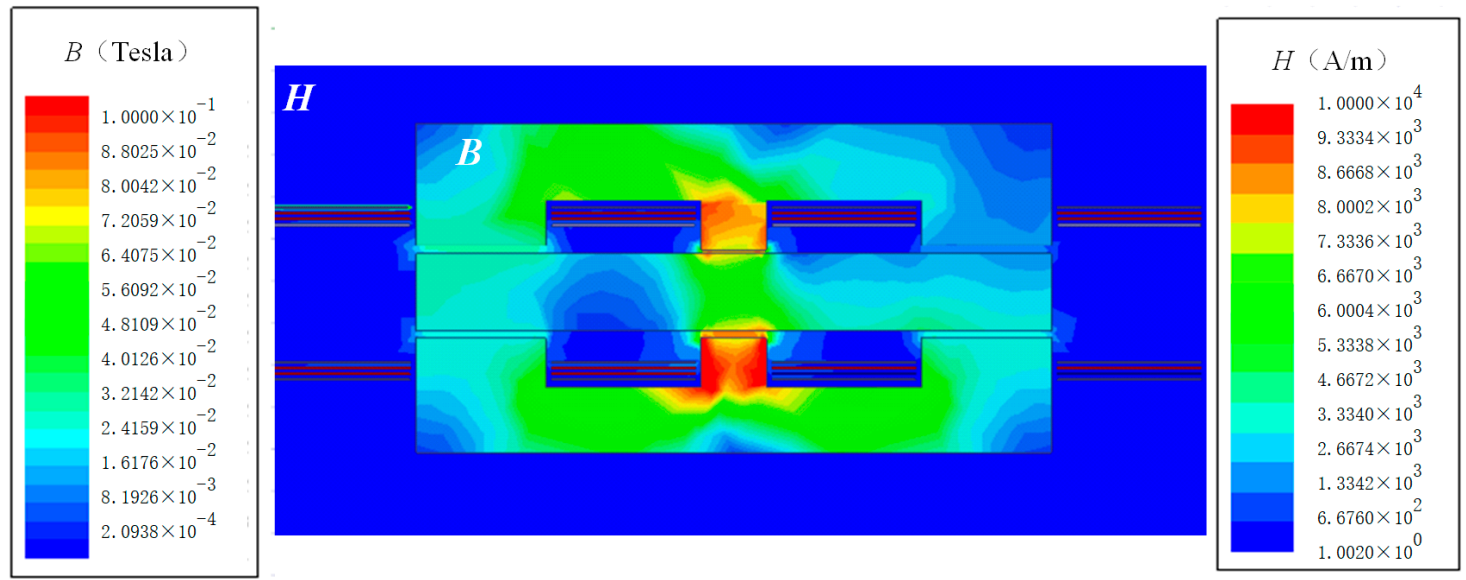

Figure 12. Flux distribution of the improved EIE (E-type and I-type and E-type) core structure.

In comparison, litz-wire-based transformers and inductors (discrete magnetics) are designed under the same parameters. The comparison between the improved EIE structure and discrete magnetics are given in Table 1. It should be noted that, the total volume and footprint of the magnetics only refer to the magnetic core, excluding the winding or skeleton.

Table 1. Comparison between the improved EIE (E-type and I-type and E-type) core structure and discrete magnetics.

\begin{tabular}{ccc}
\hline Parameter & Improved EIE Core Structure (PCB Magnetics) & Discrete Magnetics (Litz Wire) \\
\hline Inductor $L_{1}$ & Integrated & PQ2620 \\
Inductor $L_{2}$ & Integrated & PQ2620 \\
Transformer $T_{1}$ & Improved EI core structure & PQ4040 \\
Transformer $T_{2}$ & Improved EI core structure & PQ3535 \\
Total volume $\left(\mathrm{mm}^{3}\right)$ & 52,920 & 95,760 \\
Footprint $\left(\mathrm{mm}^{2}\right)$ & 1960 & 3053.6 \\
Total losses $(\mathrm{W})$ & 15.1 & 22.7 \\
\hline
\end{tabular}


From the comparison, the number of discrete magnetics is multiple, resulting in large volume and losses. This may place a restriction on its application and promotion. On this basis, the improved E core and I core structure, shown in Figure 13, is proposed to realize the complete integration of the magnetic elements in the resonant unit. Both the effective volume and footprint of magnetics are reduced. Moreover, the manufacture automation and good parasitic control can be gained with PCB magnetics. That is impossible for traditional litz wire magnetics.

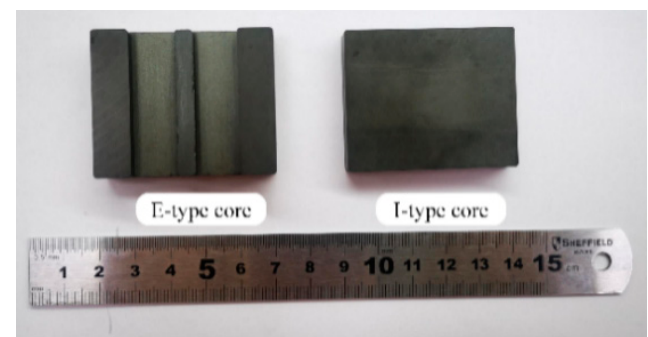

Figure 13. Proposed E-type core and I-type core.

\section{Experimental Result}

To further verify the effectiveness, a $1 \mathrm{~kW}$ prototype with the proposed integrated core structure was built in the laboratory and shown in Figure 14. The involved components and their specifications are listed in Table 2.

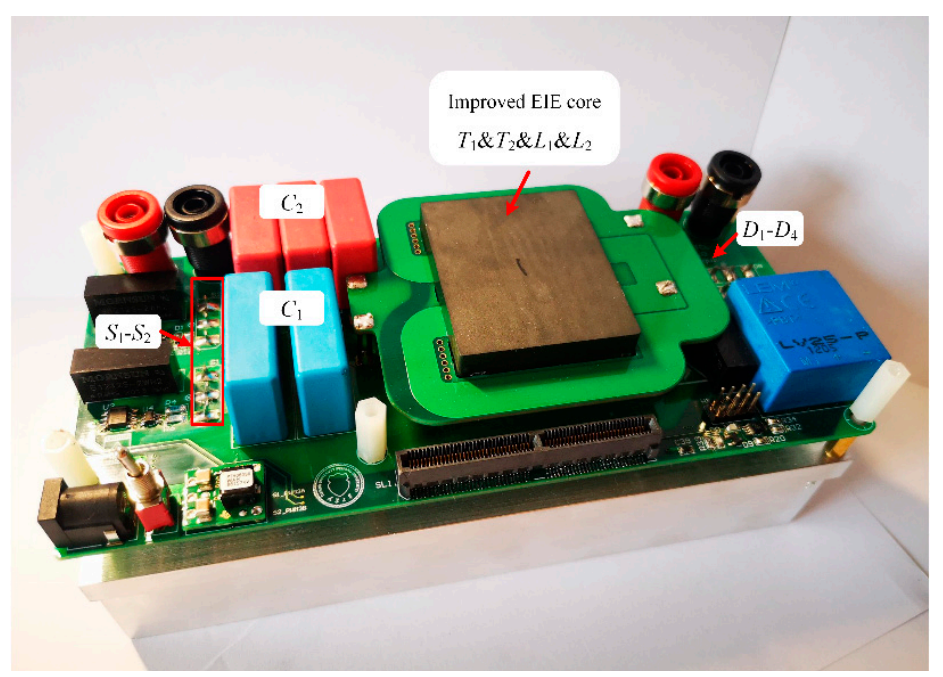

Figure 14. Experimental prototype of the proposed converter.

Table 2. Main Parameters of the CLTLC (capacitor-inductor-transformer-inductor-capacitor) converter.

\begin{tabular}{cc}
\hline Parameter & Values \\
\hline Rated power $P$ & $1 \mathrm{~kW}$ \\
Rated load $R$ & $0.9 \Omega$ \\
Rated switching frequency $f_{\mathrm{s}}$ & $300 \mathrm{kHz}$ \\
Input voltage $V_{\mathrm{in}}$ & $400 \mathrm{~V}$ \\
Output voltage $V_{\mathrm{o}}$ & $30 \mathrm{~V}$ \\
Inductor $L_{1}$ & $25 \mu \mathrm{H}$ \\
Inductor $L_{2}$ & $24 \mu \mathrm{H}$ \\
Turns ratio $n_{\mathrm{p}}{ }^{\prime}: n_{\mathrm{s}}{ }^{\prime}$ & $6: 1$ \\
Turns ratio $n_{\mathrm{p}}: n_{\mathrm{s}}$ & $0.5: 1$ \\
Capacitor $C_{1}$ & $5 \mathrm{nF}$ \\
Capacitor $C_{2}$ & $3 \mathrm{nF}$ \\
\hline
\end{tabular}


Experiments are carried out under various loads of the rated working frequency and illustrated in Figures 15-17. $v_{\mathrm{GS}}$ denotes the driving signal, $v_{\mathrm{S} 1}$ and $i_{\mathrm{S} 1}$ represent the voltage and current of power switch $S_{1}$. Similarly, $v_{\mathrm{D} 1}$ and $i_{\mathrm{D} 1}$ are defined as the corresponding quantities of diode $D_{1}$. The currents passing through $L_{1}$ and $L_{2}$ are defined as $i_{\mathrm{L} 1}$ and $i_{\mathrm{L} 2}$.

Figure 15 shows the experimental results under the rated condition and the working frequency is $300 \mathrm{kHz}$. In this case, the input voltage is $400 \mathrm{~V}$, and the output voltage is measured as $29.58 \mathrm{~V}$. It matches well with the theoretical output voltage value $(30 \mathrm{~V})$. From Figure 15, the currents of power switches and diodes all exhibit saddle-wave form. It indicates that both the fundamental and third-harmonic components are adopted to transfer active power. The switch current $i_{\mathrm{s} 1}$ takes negative value at first, and then, turns positive. $i_{\mathrm{s} 1}$ lags behind $v_{\mathrm{s} 1}$, that means, the anti-parallel diode is conducting earlier than the switch itself. So, the power switches realize the desirable zero voltage soft-switching (ZVS) characteristic. In Figure 15b, diodes also achieve the preferable zero current soft-switching (ZCS) operation. Such excellent soft-switching performances ensure a high conversion efficiency of $95.73 \%$. Both of $i_{\mathrm{L} 1}$ and $i_{\mathrm{L} 2}$ exhibit the saddle-wave form, due to the superposition of the 1 st and 3rd order components.

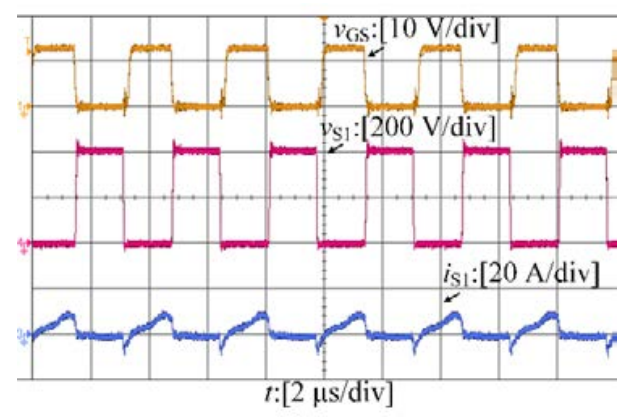

(a)

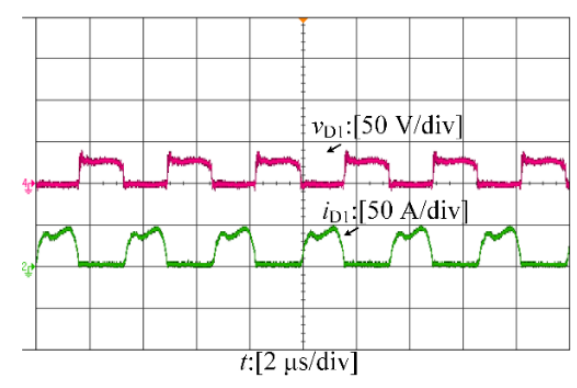

(b)

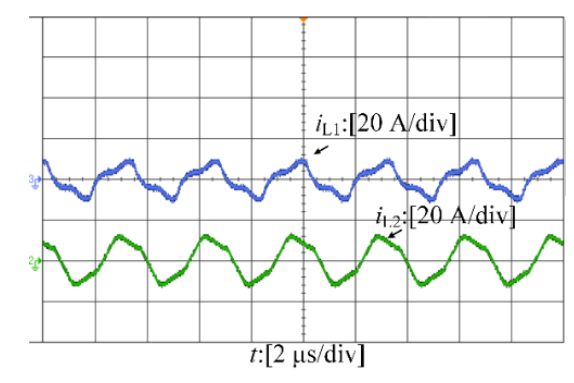

(c)

Figure 15. Experimental results at rated condition (a) waveforms of power switch $S_{1}$, (b) waveforms of diode $D_{1}$ and (c) waveforms of currents $i_{\mathrm{L} 1}, i_{\mathrm{L} 2}$. 
Experimental results under 50\% load and 30\% load are depicted in Figures 16 and 17, respectively. As can be seen, power switches and diodes still demonstrate the preferable soft-switching operation. As a consequence, the switching losses are greatly restricted among the entire load range. The measured efficiency at $50 \%$ load and $30 \%$ load are $96 \%$ and $94.25 \%$, respectively.

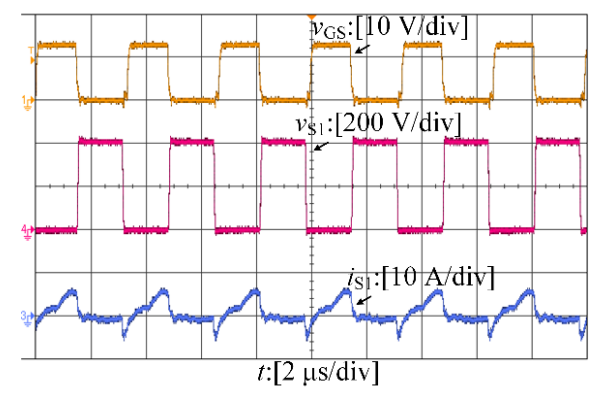

(a)

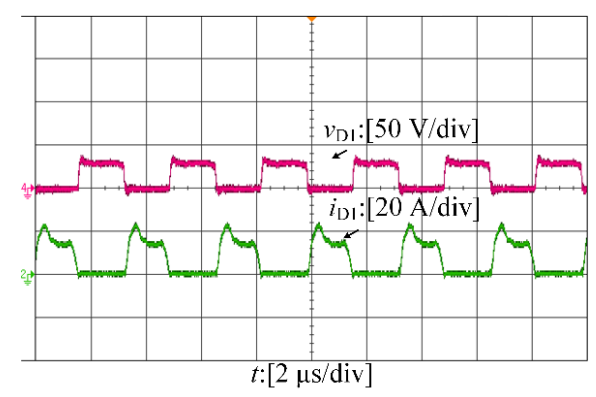

(b)

Figure 16. Experimental results at $50 \%$ condition (a) waveforms of power switch $S_{1}$, (b) waveforms of diode $D_{1}$.

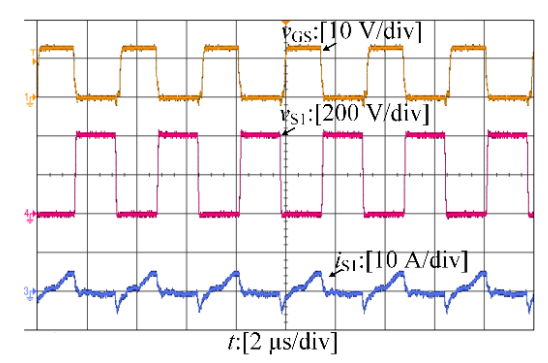

(a)

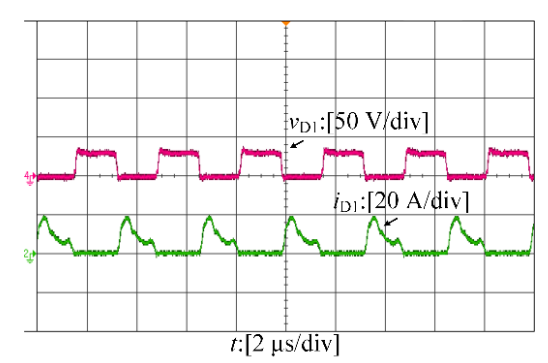

(b)

Figure 17. Experimental results at $30 \%$ condition (a) waveforms of power switch $S_{1}$, (b) waveforms of diode $D_{1}$. 
Under the rated condition, the calculated loss distributions are shown in Figure 18. As seen, the diode losses account for the highest proportion of the total losses. Beneficial from the preferable soft-switching features of the power switches, the switch losses are effectively restricted. Besides, the leakage inductor of the transformer fully serves as the resonant inductor, so the related inductor losses are completely removed. Meanwhile, the integrated core structure is alleviated with the core volume compared to discrete cores. And good response has been achieved in transformer magnetic losses. While the unbalanced winding distribution and additional leakage flux within the core may give rise to the transformer losses, but the excess losses are limited compared to its merit. In summary, relatively high-power conversion efficiency can still be guaranteed.

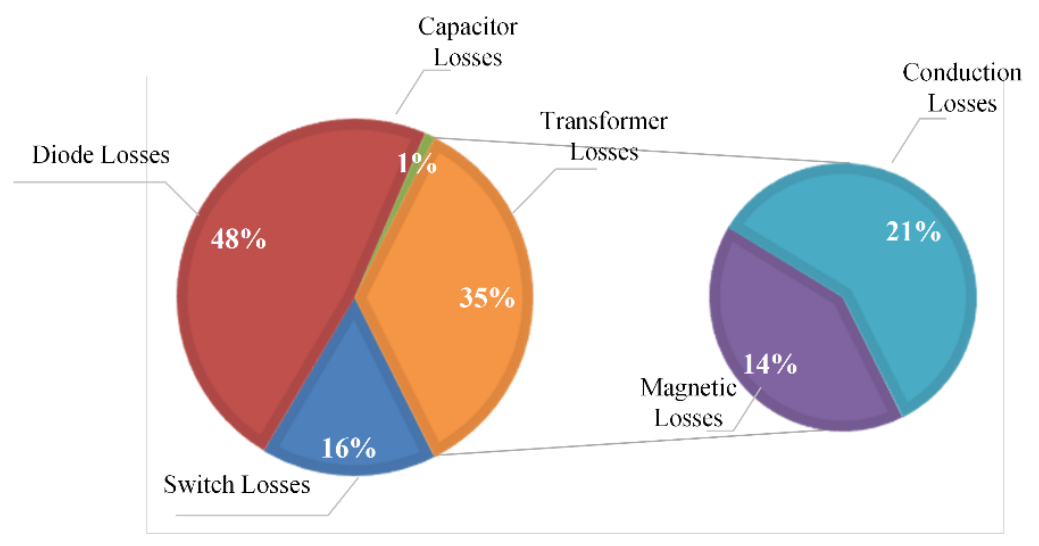

Figure 18. Loss contribution of the proposed converter at rated load.

The measured efficiency curve under different output power is plotted in Figure 19. As seen, the CLTLC resonant converter with the proposed magnetic integration design could reach a peak efficiency of $96.62 \%$ and maintain high conversion efficiency throughout. There are two main reasons for this advantage. For one thing, the eminent soft-switching features are ensured in the full load range. The switching losses are greatly restricted. For another, with the proposed structure, two transformers and two inductors are integrated into the improved EIE core geometry. Under this condition, both the size and losses of inductors are removed. It also contributes to the reduction of total magnetic losses. To sum up, the overall losses can be restricted and relatively high efficiency is achieved correspondingly.

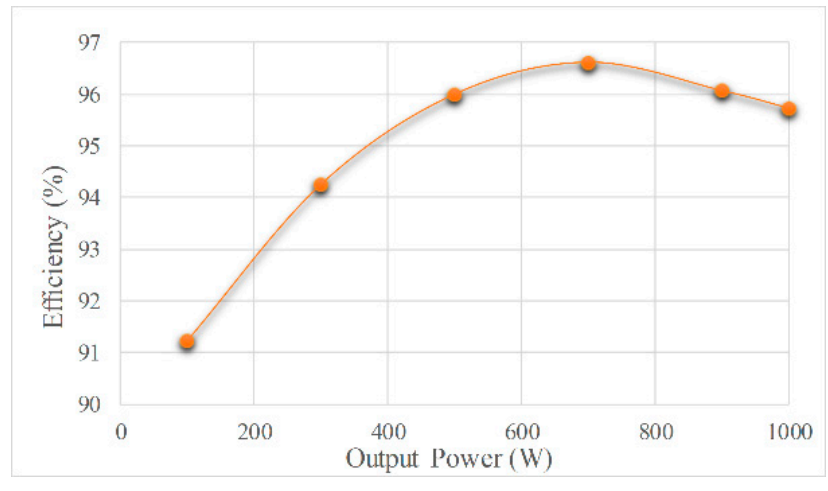

Figure 19. Efficiency curve under different output power.

Moreover, the comparison is conducted between the proposed structure and other topologies. The results are listed in Table 3.

It is clearly shown that each converter has its own pros and cons. They all show good characteristics under various working conditions. In this paper, CLTLC converter is taken as the research object 
to solve the problem of large number and volume of magnetic parts. All magnetic components are integrated into one core to achieve integration and miniaturization. With PCB magnetics, the manufacture automation and good parasitic control can be realized. Meanwhile, the outstanding soft-switching performances are obtained for both the diodes and power switches. The third order harmonics can be effectively transmitted by appropriate parameter design. Thus, the overall efficiency can be ensured.

Table 3. Comparison of performances among different topologies.

\begin{tabular}{cccccc}
\hline $\begin{array}{c}\text { Topology } \\
\text { Descriptions }\end{array}$ & $\begin{array}{c}\text { Input } \\
\text { Voltage } \boldsymbol{V}_{\text {in }}\end{array}$ & $\begin{array}{c}\text { Rated } \\
\text { Power } \boldsymbol{P}\end{array}$ & $\begin{array}{c}\text { Rated Operating } \\
\text { Frequency } \boldsymbol{f}_{\mathbf{s}}\end{array}$ & Peak Efficiency & $\begin{array}{c}\text { Magnetic } \\
\text { Integration }\end{array}$ \\
\hline HB-2LLC [23] & $400 \mathrm{~V}$ & $1.5 \mathrm{~kW}$ & $170 \mathrm{kHz}$ & $95.21 \%$ & No \\
PWM LLC [24] & $390 \mathrm{~V}$ & $1 \mathrm{~kW}$ & $100 \mathrm{kHz}$ & $96.7 \%$ & No \\
SA-VSR [25] & $400 \mathrm{~V}$ & $1.5 \mathrm{~kW}$ & $100 \mathrm{kHz}$ & Above $95 \%$ & No \\
LLC [26] & $380 \mathrm{~V}$ & $100 \mathrm{~W}$ & $1 \mathrm{MHz}$ & Above $95 \%$ & Yes \\
CLLC [27] & $350 \mathrm{~V}$ & $6.6 \mathrm{~kW}$ & $500 \mathrm{kHz}$ & $97.8 \%$ & Yes \\
CLTLC & $400 \mathrm{~V}$ & $1 \mathrm{~kW}$ & $300 \mathrm{kHz}$ & $96.6 \%$ & Yes \\
\hline
\end{tabular}

\section{Conclusions}

The CLTLC multi-resonant converter suffers from the problems of multiple magnetic components, large volume and high-power losses. To deal with the above issues, an entire magnetic integration method with the improved EIE core structure is designed in this paper. This scheme could integrate two transformers and two inductors into one core successfully. Rather than the evenly distributed winding in matrix transformer, the uneven winding distribution is adopted to increase the leakage inductance. By introducing an air gap to the middle core leg, the flexible control of the transformer's magnetizing inductor and leakage inductor can be realized. Moreover, the detailed mathematical analysis and reluctance model are elaborated to validate the feasibility of the proposed structure. Besides, the detailed winding arrangement is given and the related simulation model is established in Maxwell software. In the end, a $1 \mathrm{~kW}$ prototype is built in the laboratory. The converter achieves preferable soft-switching characteristics within the entire load range and guarantees high conversion efficiency throughout. The peak efficiency reaches $96.62 \%$.

Author Contributions: Conceptualization, R.L.; Formal analysis, R.L. and F.H.; Resources, Y.W.; Software, Q.C.; Validation, Z.M. All authors have read and agreed to the published version of the manuscript.

Funding: This research was funded by the National Key R\&D Program of China (Grant: 2018YFB0904700).

Conflicts of Interest: The authors declare no conflict of interest.

\section{Abbreviations}

The following abbreviations are used in this manuscript:

PCB printed circuit board

CLTLC capacitor-inductor-transformer-inductor-capacitor

UI U-type and I-type

EI E-type and I-type

EIE E-type and I-type and E-type

\section{References}

1. Yi, K. Capacitive Coupling Wireless Power Transfer with Quai-LLC Resonant Converter Using Electric Vehicle's Windows. Electronics 2020, 9, 676. [CrossRef]

2. Jia, P.; Yuan, Y. Analysis and Implementation of LC Series Resonant Converter with Secondary Side Clamp Diodes under DCM Operation for High Step-Up Applications. J. Power Electron. 2019, 19, 363-379.

3. Shen, Y.; Wang, H.; Shen, Z.; Yang, Y.; Blaabjerg, F. A 1-MHz Series Resonant DC-DC Converter with a Dual-Mode Rectifier for PV Microinverters. IEEE Trans. Power Electron. 2018, 34, 6544-6564. [CrossRef] 
4. Yi, K. Output Voltage Analysis of Inductive Wireless Power Transfer with Series LC and LLC Resonance Operations Depending on Coupling Condition. Electronics 2020, 9, 592. [CrossRef]

5. Chen, Y.; Wang, H.; Hu, Z.; Liu, Y.-F.; Liu, X.; Afsharian, J.; Yang, Z. LCLC Converter With Optimal Capacitor Utilization for Hold-Up Mode Operation. IEEE Trans. Power Electron. 2018, 34, 2385-2396. [CrossRef]

6. Wu, H.; Jin, X.; Hu, H.; Xing, Y. Multielement Resonant Converters with a Notch Filter on Secondary Side. IEEE Trans. Power Electron. 2015, 31, 3999-4004. [CrossRef]

7. Guan, Y.; Wang, Y.; Xu, D.G.; Wang, W. A 1 MHz Half-Bridge Resonant DC/DC Converter Based on GaN FETs and Planar Magnetics. IEEE Trans. Power Electron. 2017, 32, 2876-2891. [CrossRef]

8. Wang, Y.-F.; Han, F.; Yang, L.; Wang, C.; Chen, B.; Xu, R. A Novel D-CLT Multi-Resonant DC-DC Converter with Reduced Voltage Stresses for Wide Frequency Variation Applications. IEEE Trans. Power Electron. 2018, 34, 4509-4523. [CrossRef]

9. Ouyang, Z.; Andersen, M.A.E. Overview of Planar Magnetic Technology—Fundamental Properties. IEEE Trans. Power Electron. 2013, 29, 4888-4900. [CrossRef]

10. Ouyang, Z.; Thomsen, O.C.; Andersen, M.A.E. Optimal Design and Tradeoff Analysis of Planar Transformer in High-Power DC-DC Converters. IEEE Trans. Ind. Electron. 2010, 59, 2800-2810. [CrossRef]

11. Mu, M.; Lee, F.C. Design and Optimization of a 380-12V High-Frequency, High-Current LLC Converter with GaN Devices and Planar Matrix Transformers. IEEE J. Emerg. Sel. Top. Power Electron. 2016, 4, 854-862. [CrossRef]

12. Buccella, C.; Cecati, C.; De Monte, F. A Coupled Electrothermal Model for Planar Transformer Temperature Distribution Computation. IEEE Trans. Ind. Electron. 2008, 55, 3583-3590. [CrossRef]

13. Prieto, R.; Oliver, J.A.; Cobos, J.A.; Christini, M. Magnetic Component Model for Planar Structures Based on Transmission Lines. IEEE Trans. Ind. Electron. 2009, 57, 1663-1669. [CrossRef]

14. Quirke, M.T.; Barrett, J.J.; Hayes, M. Planar magnetic component technology-A review. IEEE Trans. Compon. Hybrids Manuf. Technol. 1992, 15, 884-892. [CrossRef]

15. Schauwers, J.-P.; Nunes, C.; Velaerts, B.; Robert, F.; Mathys, P. Planar transformer technology applied to AC/DC conversion. In Proceedings of the 21st International Telecommunications Energy Conference, INTELEC'99 (Cat. No.99CH37007), Copenhagen, Denmark, 9 June 1999.

16. Quinn, C.; Rinne, K.; O’Donnell, T.; Duffy, M.; Mathuna, C.O. A Review of Planar Magnetic Techniques and Technologies. In Proceedings of the 16th Annual IEEE Applied Power Electronics Conference and Exposition, APEC 2001 (Cat. No. 01CH37181), Anaheim, CA, USA, 4-8 March 2001; pp. 1175-1183.

17. Chen, W.; Lee, F.C.; Zhou, X.; Xu, P. Integrated planar inductor scheme for multi-module interleaved quasi-square-wave (QSW) DC/DC converter. In Proceedings of the 30th Annual IEEE Power Electronics Specialists Conference, Record (Cat. No.99CH36321), Charleston, SC, USA, 1 July 1999.

18. Ouyang, Z.; Sen, G.; Thomsen, O.C.; Andersen, M.A. Analysis and Design of Fully Integrated Planar Magnetics for Primary-Parallel Isolated Boost Converter. IEEE Trans. Ind. Electron. 2012, 60, 494-508. [CrossRef]

19. Biela, J.; Kolar, J.W. Electromagnetic integration of high power resonant circuits comprising high leakage inductance transformers. In Proceedings of the 2004 IEEE 35th Annual Power Electronics Specialists Conference (IEEE Cat. No.04CH37551), Aachen, Germany, 20-25 June 2004.

20. Zhang, J.; Ouyang, Z.; Duffy, M.C.; Andersen, M.A.E.; Hurley, W.G. Leakage Inductance Calculation for Planar Transformers With a Magnetic Shunt. IEEE Trans. Ind. Appl. 2014, 50, 4107-4112. [CrossRef]

21. Huang, D.; Ji, S.; Lee, F.C. LLC Resonant Converter with Matrix Transformer. IEEE Trans. Power Electron. 2014, 29, 4339-4347. [CrossRef]

22. Erickson, R.W.; Maksimovic, D. Fundamentals of Power Electronics, 2nd ed.; Springer: Berlin, Germany, 2001.

23. Imran, M.; Iqbal, S. A Wide Ouput Range HB-2LLC Resonant Converter with Hybrid Rectifier for PEV Battery Charging. IEEE Trans. Power Electron. 2017, 3, 520-531.

24. Wang, H.; Li, Z. A PWM LLC Type Resonant Converter Adapted to Wide Output Range in PEV Charging Applications. IEEE Trans. Power Electron. 2018, 33, 3791-3801. [CrossRef]

25. Wu, H.; Li, Y.; Xing, Y. LLC Resonant Converter with Semi-active Variable Structure Rectifier. IEEE Trans. Power Electron. 2016, 31, 3389-3394. [CrossRef] 
26. Li, M.; Ouyang, Z.; Andersen, M.A.E. High-Frequency LLC Resonant Converter with Magnetic Shunt Integrated Planar Transformer. IEEE Trans. Power Electron. 2018, 34, 2405-2415. [CrossRef]

27. Li, B.; Li, Q.; Lee, F.C.; Yang, Y. A symmetrical resonant converter and PCB transformer structure for common mode noise reduction. In Proceedings of the 2017 IEEE Energy Conversion Congress and Exposition (ECCE), Cincinnati, OH, USA, 1-5 October 2017; pp. 5362-5368. 